Research Article

\title{
An Ethnobotanical and Ethnopharmacological Survey of Cannabis Sativa of Taounate Region in Northern Morocco
}

\author{
Mouna Bouarfa*1, Siham Lebtar ${ }^{2}$, Smahane Boukhira $^{1}$, Dalila Bousta ${ }^{1}$ \\ ${ }^{1}$ Laboratory of Neuroendocrinology and Nutritionnel and Climatic Environment, University of Sidi Mohamed Ben Abdellah, FSDM-Fez, Morocco. \\ 'Laboratory of Biotechnology, Environnement and Quality, Departement of Biology, University Ibn Tofail, Faculty of Sciences, Kenitra, Morocco. \\ *Corresponding author's E-mail: mounabouarfa03@gmail.com
}

Received: 18-07-2020; Revised: 22-09-2020; Accepted: 28-09-2020; Published on: 20-10-2020.

\begin{abstract}
The objective of this present survey is to collect some information about Cannabis Sativa as a medicinal and recreational plant collected from three sites of Taounate region. In this survey, 120 informants were interviewed about cannabis uses. The range of the age of the interviewees varies between 17 and 60 years. The results of this investigation showed, on the one hand, a difference between people concerning cannabis uses. Some of them use it for recreational purposes, while others use it for therapeutic reasons, such as treatment of anxiety, diabetes, entero-gastric diseases ("chem" “الشم"), dental pain, and others. On the other hand, this survey also revealed that the interviewees are strongly asserted that cannabis is effective in treating diabetes, insomnia and pain. In addition, this survey showed that cannabis seeds are widely used in the diet of laying hens.
\end{abstract}

Keywords: Cannabis sativa, Ethnobotanical, Survey, Taounate, Morocco.

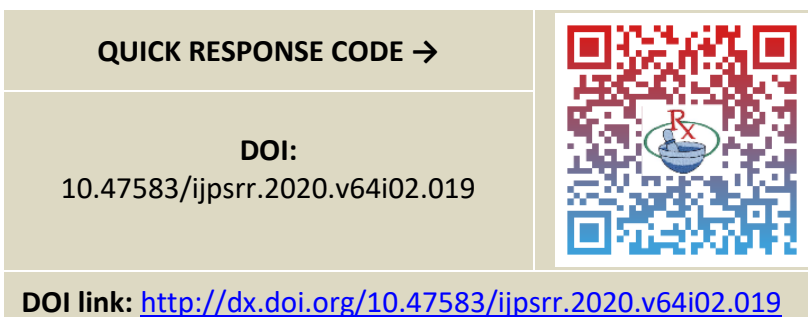

\section{INTRODUCTION}

$\mathrm{n}$ almost all the reports and thesis developed on cannabis and its products, this reality appears: Cannabis products are the subject of the largest drug trafficking in the world. Its use is illegal and punishable by fines and prison terms according to the laws ${ }^{1,2}$, because of the social consequences which can engender for the population ${ }^{3}$, and therefore, it is at the center of political debates, as well as medical and social ${ }^{4}$.

The United Nations Office on Drugs and Crime in its 2006 report shows that 5200 tons of herb of cannabis and 1000 tons of resin were seized. Almost no country in the world is immune to cannabis trafficking. At the same time, cannabis also remains the most widely used drug in the world, with 166 million users as an estimated number, which corresponds to around $4 \%$ of the world's population aged from 15 to 64 years ${ }^{5}$. At the same time, production methods have become more sophisticated, with the result the availability on the illicit markets of wide range of cannabis products in different levels of the main psychoactive ingredient, the delta-9 tetrahydrocannabinol (THC).

Unlike the several countries that have already initiated scientific studies to have a database on their cannabis varieties, in the horizon of legalizing its cultivation as soon as possible, Morocco remains very faithful to the international conventions that prohibit the cultivation of the plant, forming a solid barrier against any scientific initiative that aims at making research on the cannabis sativa of the Kingdom, and thus give a hope for all stakeholders (industries and cannabis growers ...) to cultivate and industrialize cannabis products legally.

The present study aims to make a data base of information about the uses of cannabis in Taounate region.

\section{MATERIALS AND METHODS}

\section{Presentation of Taounate region}

The province of Taounate is located in the area pre-Rifain of the Kingdom. It is composed of 44 rural municipalities and 5 urban communes. Its total area is $5616 \mathrm{~km}^{2}$. Its economy is mainly articulated around the agriculture (grain farming, fig trees...) and particularly the culture of cannabis which has become more and more of great importance for the peasants.

\section{Geographical data}

The territory of Taounate is constituted overall by two distinct parts.

A Northern part to mountainous terrain attached to the Rifain domain. It constitutes about $40 \%$ of its area. The maximum altitudes peak from the East to the West, 1730 $\mathrm{m}$ (Jbel Tajerfet) $820 \mathrm{~m}$ approximately (Jbel Al Bibane). The minimum requirements follow in the same direction the bed of Oued Ourgha and vary from 300 to $80 \mathrm{~m}$.

A southern part to hilly terrain and eventful, attached to the area pre-rifain and which constitutes about $60 \%$ of its area. The altitudes are relatively mitigated and vary from $150 \mathrm{~m}$ (Wadi Innaouen) at $1000 \mathrm{~m}$ to Jbel Zeddour. Within 
this rugged terrain, there are a few small plains that are individualized along the course of the water.

The 3 sites of study are located as follows:
Khlalfa in the northern part, Tafrant in the south western part and Oudka in the north-western part. Oudka has a relief more accentuated than the two first sites (Fig.1).

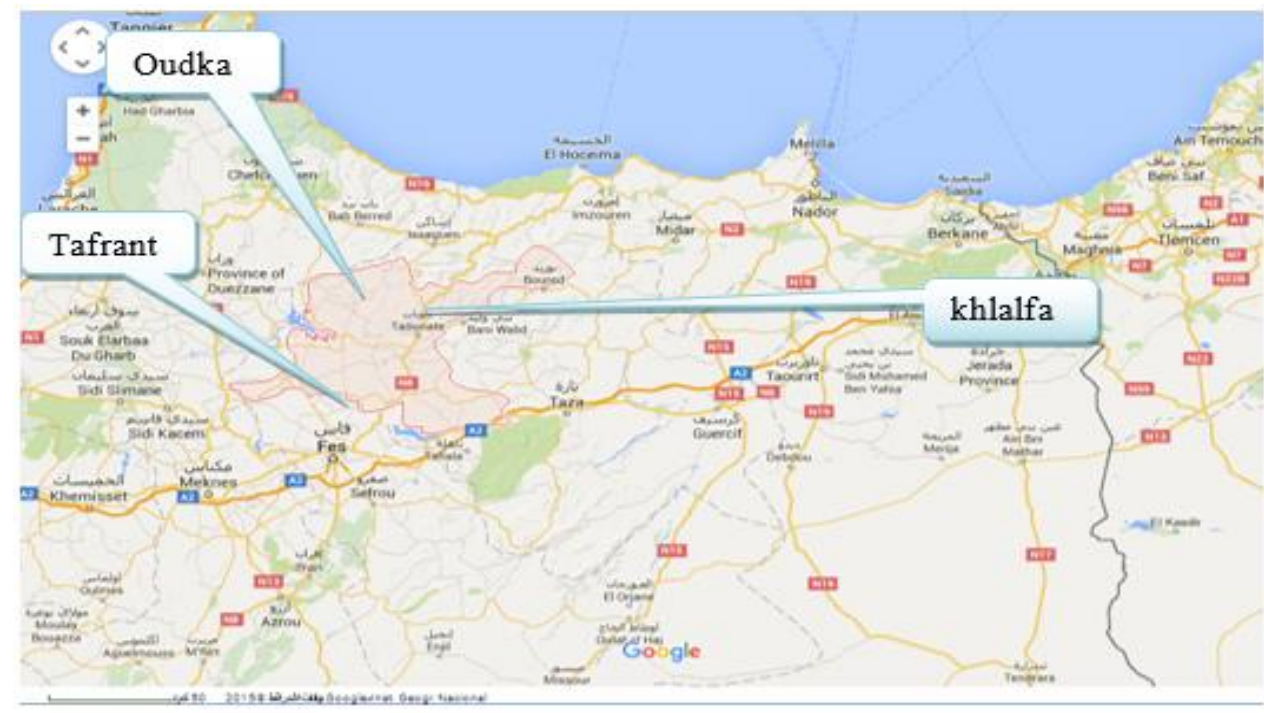

Figure 1: Map showing the location of the study area

\section{Data collection}

This study was carried in April 2016 using a well-structured questionnaire. The set questions contained the names of varieties of cannabis, the therapeutic use of cannabis, the modes of use...

\section{Ethical aspect}

The data has been collected with respect for confidentiality and anonymity. No nominative data has been transmitted to anyone.

\section{Data analysis}

The data was entered and analyzed by Microsoft Excel.

\section{RESULTS}

\section{Population surveyed}

The respondents are mainly represented by herbalists, farmers and users. Their age varies between 17 and 60 years (Fig. 2). They represent $98.33 \%$ of male and $1.67 \%$ of female (Fig. 3), their education levels are distributed as follows: $35 \%$ primary $32.50 \%$ college, $25 \%$ secondary, $4.17 \%$ are illiterate and $3.33 \%$ are academics (Fig .4).

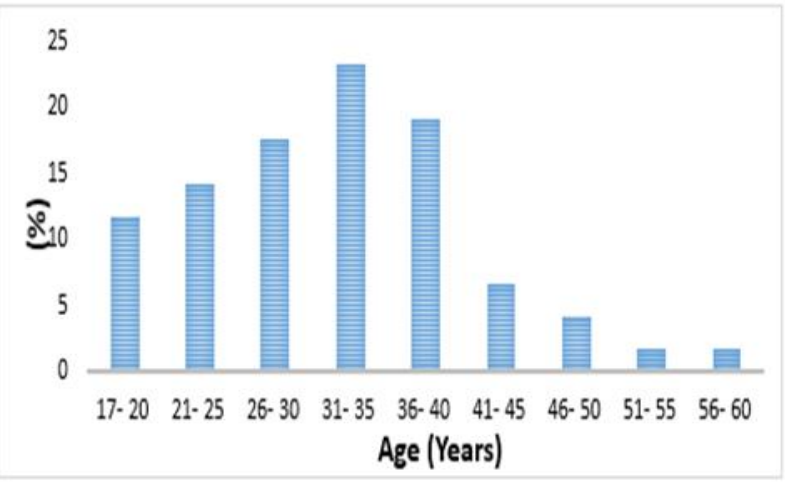

Figure 2: The age of the interviewees

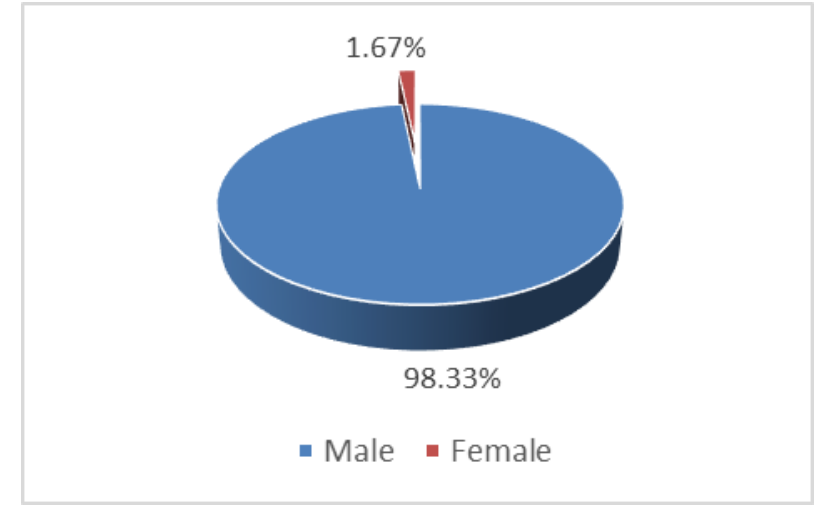

Figure 3: Distribution of interviewees according to the sex

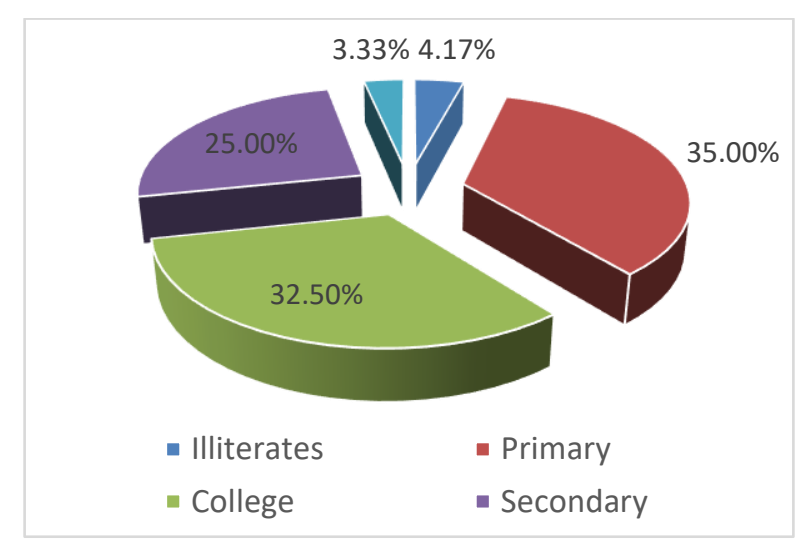

Figure 4: Distribution of the respondents according to the level of education

\section{Cannabis products in the Moroccan market}

According to the herbalists interviewed, the products marketed are mainly obtained from cannabis seeds. These products, which are called "hash oil" or "green hemp shampoo", are sometimes mixed with other plants and macerated in vegetable oil (Fig. 5). 

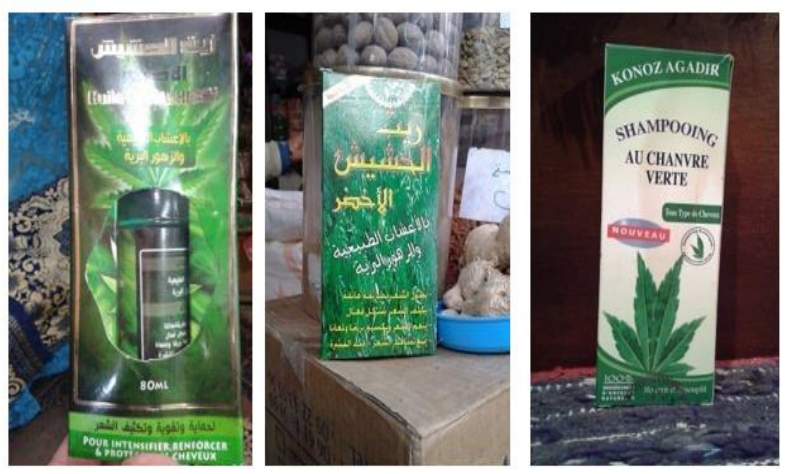

Figure 5: Examples of cannabis products marketed in Morocco

\section{Forms of cannabis use}

Cannabis resin is used either directly powdered (Fig. 6), or compressed (Fig. 7) or compressed and lightly heated. Cannabis can be inhaled from the combustion of a small amount of hashish (Fig. 8), or as a joint or Sebsi (Fig. 9). This last is obtained from the mixture of the herb of cannabis and Nicotiana tabacum "Taba Beldia" (Fig. 10).

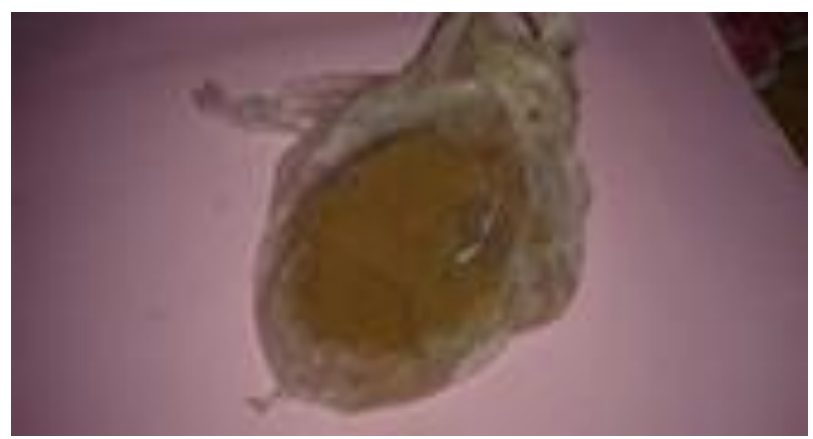

Figure 6: Uncompressed "hashish"

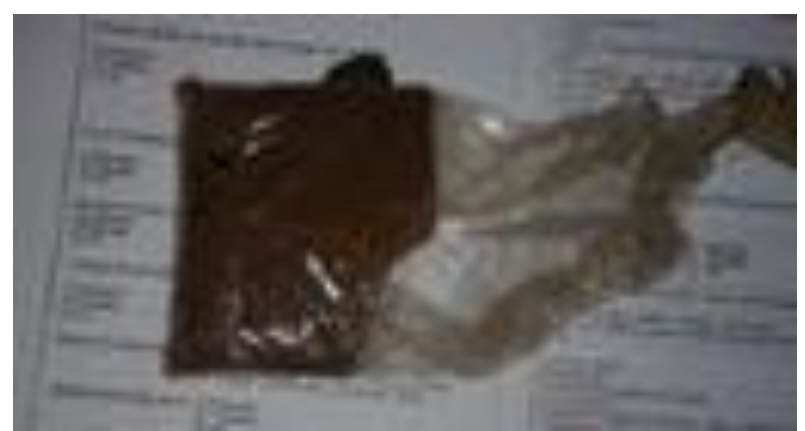

Figure 7: Compressed "hashish"

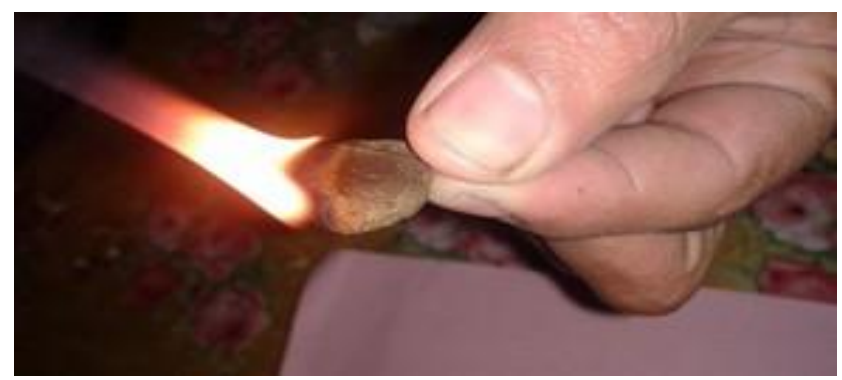

Figure 8: Burning of a small amount of hashish

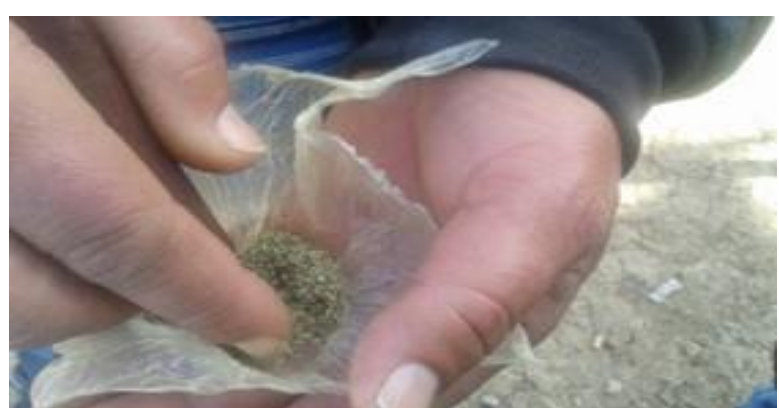

Figure 9: Consumption of cannabis in herb form "Sebsi"

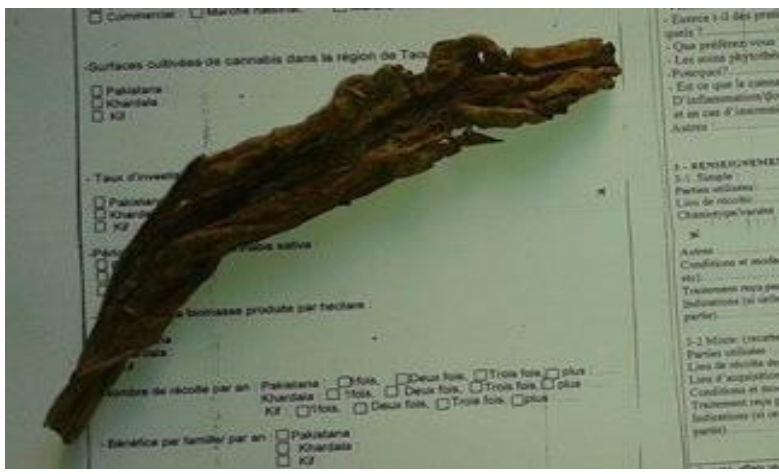

Figure 10: Nicotiana tabacum (Taba Beldia)

\section{Medical and cannabis care}

In this survey, $50 \%$ of respondents replied that they prefer herbal cannabis treatments rather than adopting medical care, and they justified their responses by the availability of cannabis, it's cheaper cost and loss of confidence, sometimes, in modern medicine, while the remaining $50 \%$ prefer medical care (Fig. 11).

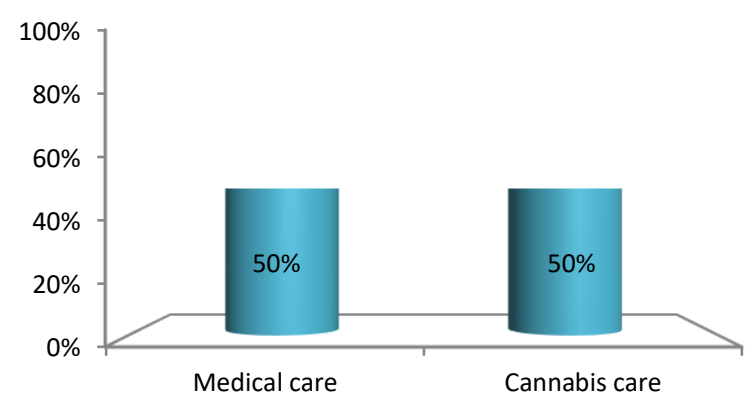

Figure 11: Medical and cannabis care

\section{Medicinal uses of cannabis}

According to the survey carried out, cannabis is used to treat a number of health problems such as anxiety, dental pain, entero-gastric diseases "Chem" "الشم", blood sugar, scarring injury, asthma and stomach irritation (Fig. 12). 


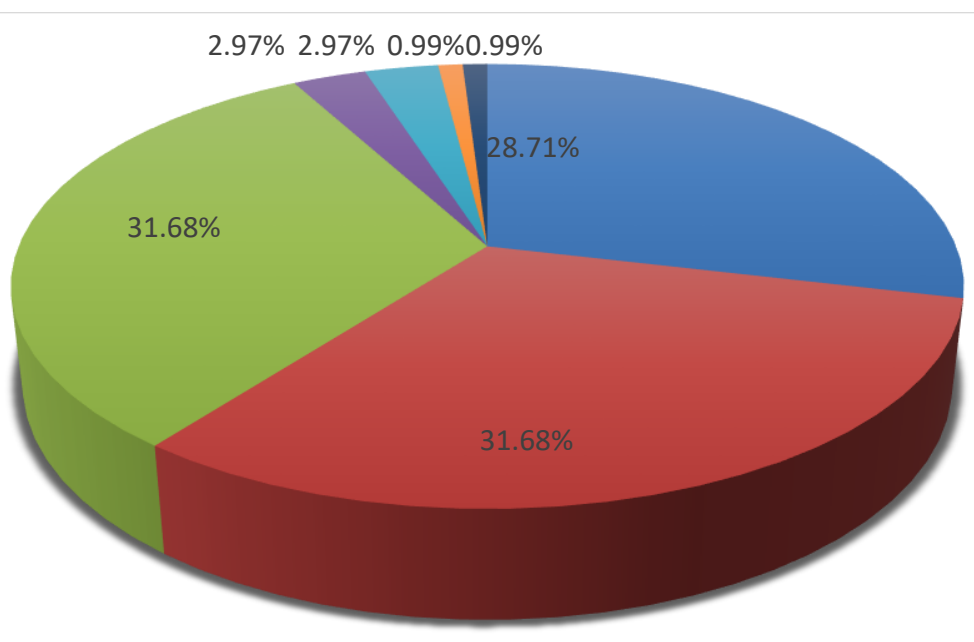

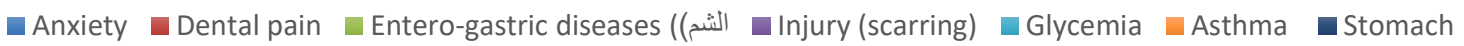

Figure 12: Medicinal uses of cannabis

\section{Modes of cannabis use}

Cannabis is used in different modes, inhaled as a Sebsi (mixture of the herb of cannabis and Taba Beldia) or as a joint, inhaled directly from the combustion of a small amount of hashish, or administered orally as an infusion (Fig. 13).

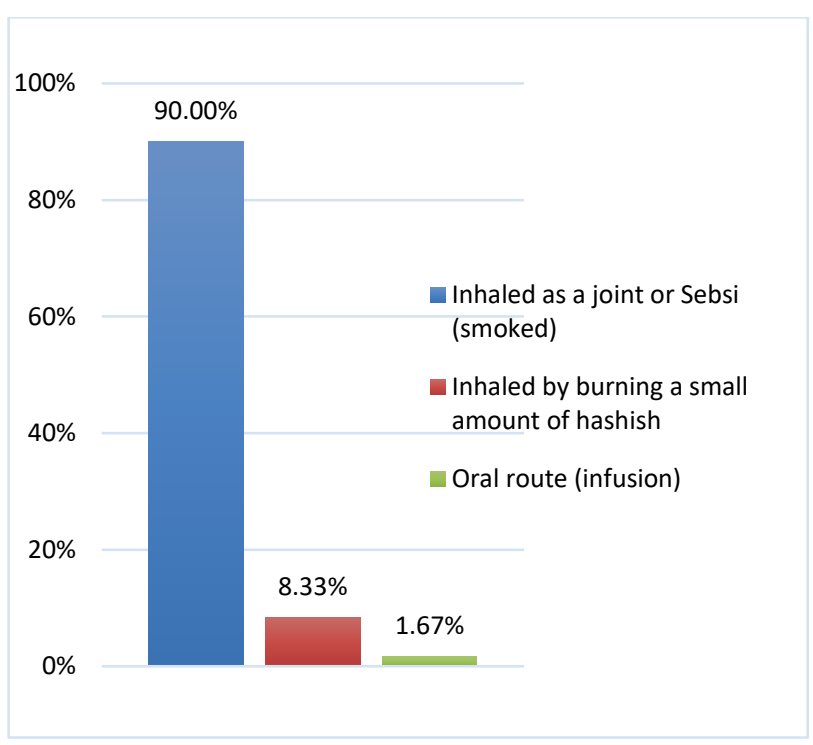

Figure 13: Modes of cannabis use

\section{Export to the international market}

Most of the respondents answered that Kif (Beldia) is the variety most used by consumers here in Morocco, but the other two varieties, Khardala and Pakistana (Pakistania), are cultivated mainly for their export to the international market (because of their high THC content). $50 \%$ of the people replied that the Pakistana variety contains more drugs and it is exported to the international market for medicinal or recreational purposes while $43,33 \%$ say that for Khardala (Fig.14).

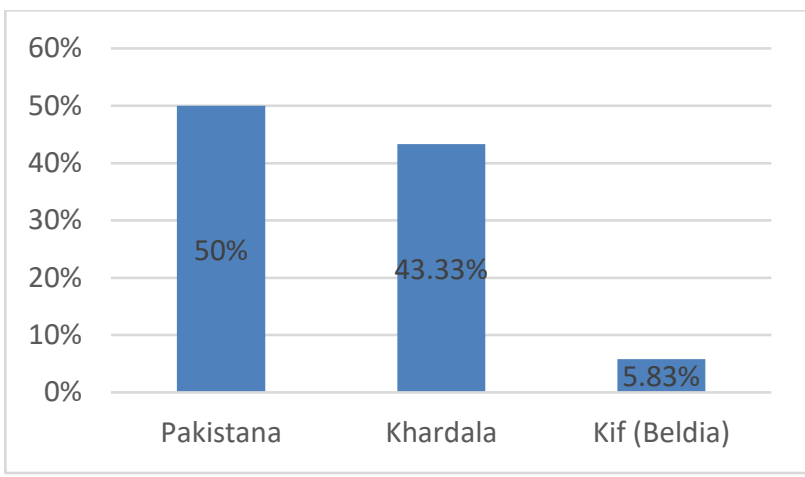

Figure 14: Export to the international market

\section{Cannabis and diabetes}

A diabetes record was made with the delegation of the Taounate health ministry using data from 3 sites that cultivate cannabis (Khlalfa, Oudka and Tafrant) and 3 other sites that do not cultivate it (Bouarous, Mkanssa and Tissa). The result of this survey shows a reduction in the number of patients diagnosed and manifesting diabetes in sites where there is cannabis cultivation compared to the sites where this culture does not exist (Fig. 15).

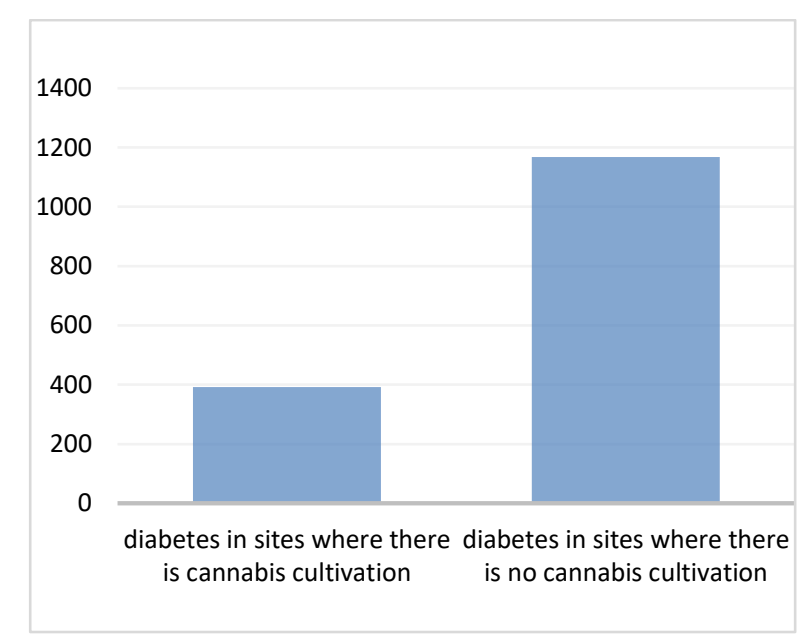

Figure 15: Cannabis cultivation and diabetes 


\section{Cannabis for pain and insomnia}

To evaluate these two types of health problems in the population surveyed, the results of the survey revealed that $52 \%$ of respondents answered that cannabis is effective in pain, while $48 \%$ considered it effective in insomnia (Fig. 16).

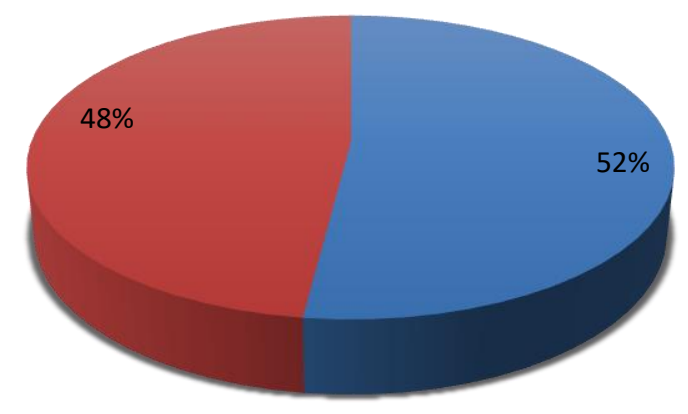

Effectiveness of cannabis in pain

Effectiveness of cannabis in insomnia

Figure 16: Effectiveness of cannabis in pain and insomnia

\section{Side effects of cannabis}

Nervousness, increased body temperature, breathing problems, loss of concentration and phobia, are the side effects of a severe cannabis use for beginners (especially Pakistana and Khardala), while skin allergy is linked to contact with the plant during harvest.

\section{Correctors of the side effects of cannabis}

Lben, orange / lemon and unsweetened coffee are the correctors of the adverse effects of cannabis inventoried from the population surveyed. $70 \%$ of them say that Lben (fermented milk from which the butter is eliminated) is the most effective corrector, $20 \%$ advise taking an orange / lemon juice, while $10 \%$ advise taking an unsweetened coffee (Fig.17).

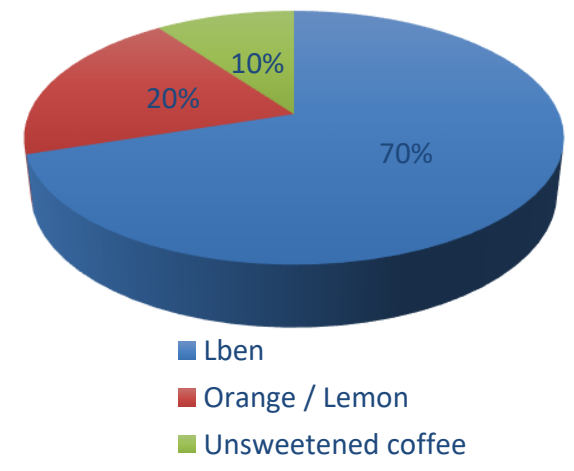

Figure 17: Correctors of the side effects of cannabis

\section{Cannabis seed uses}

For the use of cannabis seeds, the exploitation of the survey data showed that the majority of the respondents stated that these seeds were used as a diet of laying hens, while others reported using these seeds in treating stomach problems by eating powdered seeds mixed with honey. As for the oil of these seeds, the majority of the respondents declared its effectiveness in hair growth.

\section{DISCUSSION}

First of all, it must be pointed out to the difficulty of collecting information from the survey carried out in the study sites. Cannabis cultivators have always afraid of the authorities; they have continuous doubt about our identities as investigators. For this reason, we were unable to interview more than 120 people.

Cannabis has interested researchers around the world, and their scientific papers have shed light on its recreational and therapeutic activities, as well as its economic and spiritual uses ${ }^{5-8}$.

From scientific research done on cannabis, CBD, a major component of this plant as important as THC, effectively reduces high blood glucose levels ${ }^{9}$. Another study indicates that oral administration of $\Delta 9$ tetrahydrocannabinol causes dilation of the respiratory tracts in patients with acute pulmonary disease ${ }^{10}$. Cannabis also has an analgesic effect ${ }^{11,12}$.

Several other studies have shown the therapeutic effects of cannabis, it has an anti-edema, antidepressant effect and efficacy in reducing anxiety in patients with social anxiety disorder by CBD, CBC and THC that it contains ${ }^{13-15}$. The immunomodulatory effect is also present in the illicit plant through the use of unheated extracts containing THCA ${ }^{16}$. Colon cancer also finds combattants in a high CBD BDS (cannabidiol botanical drug substance) extract. This extract attenuates colon carcinogenesis by inhibiting the proliferation of cancer cells via the activation of the CB1 and $\mathrm{CB} 2$ receptors ${ }^{17}$. Generally, cannabinoids have an apoptotic effect on cancer cells. They can affect the angiogenesis of tumor cells, their migration, invasion, adhesion and metastasis ${ }^{18}$.

Another report shows the effectiveness of cannabis as a medicinal plant in a study of the inhibitory activity of essential oils in industrial cannabis on microbial growth. These essential oils have been shown to be effective in inhibiting the growth of Gram + and Gram - bacteria as well as yeasts. These results may have interesting applications to control spoilage and foodborne pathogens agents and phytopathogens micro-organisms ${ }^{19}$. Cannabis also contains two flavonoids biologically active, Cannflavin A and $B$ which have anti-microbial and anti-protozoan activity ${ }^{20}$

Regarding the results of this survey, we will focus on discussing the therapeutic uses of cannabis on diabetes, pain and insomnia, and lastly the use of its seeds in the diet of laying hens.

As for the relationship of cannabis and diabetes and based on the result of an inventory carried out by the delegation of the Ministry of Health of the city of Taounate. The number of people who visited hospitals of the region in 
2017 and who developed diabetes was lower in three regions where cannabis cultivation is intense (Khlalfa, Tafrant and Oudka). While this number, was high in three other regions (Tissa, Mkanssa and Bouarous) where the cultivation of this plant is totally absent. This result can have several explanations. On the one hand, people living in the areas where the plant is not cultivated, may have genetic diabetes and consanguineous marriage may have contributed more to its spread than other areas or the lifestyle of this population which may have contributed to the development of obesity, one of the main causes of diabetes. On the other hand, another explanation can be given, is that cannabis cultivation could have a positive effect in preventing or treating the disease. This latter interpretation may have a justification in some scientific publications showing the therapeutic effect of cannabis against diabetes, especially type 2 . In this regard, it has been assumed that the prevalence of diabetes would be reduced in cannabis users due to the presence of one or more cannabinoids due to their immunomodulatory and anti-inflammatory properties ${ }^{21}$. Also, it was evaluated that the use of marijuana was associated with a decrease in the prevalence of diabetes mellitus in a study carried out on a population of adults aged between 20 and 59 years ${ }^{22}$.

For the effect of cannabis against pain, cannabis has been shown to be effective in the treatment of pain in several clinical and experimental studies. In this context, a clinical study was conducted on a population of 16 patients with diabetic neuropathy pain, when they consumed the cannabis by inhalation; the pain was reduced. This efficacy may be linked to the analgesic effect of cannabis ${ }^{23}$. The effect of cannabis in the treatment of insomnia is also proved and documented by previous researches. Indeed, work in this context has shown that the use of cannabis caused a decrease in sleep latency and an increase in slow sleep 24-26. In addition, chronic cannabis use may be associated with sleep habituation and improved properties of slow sleep ${ }^{26-28}$.

Regarding their nutritional value in relation to their use as a source of energy and essential fatty acids ${ }^{29}$, the use of cannabis seeds in the diet of hens is addressed by several publications and their effectiveness has already been proven by several scientific researches. Indeed, the addition of seeds and oil of cannabis in the diet of laying hens are well tolerated by them and they can serve as alternatives to produce eggs with a high content of omega 3 ( $\alpha$ - linolenic acid). In addition, these products have also been shown to be safe as they do not affect the performance and blood chemistry of these hens ${ }^{30,31}$.

\section{CONCLUSION}

The analysis of Cannabis sativa uses in the province of Taounate has provided us new information, which not only offers scientific recognition of this plant considered mainly illicit but could open new avenues for interesting therapeutic investigations.

\section{REFERENCES}

1. Laurent K, Michel R, Le cannabis, Fiche technique, 2006.

2. Costes JM, Cannabis, données essentielles, Saint-Denis, OFDT, 2007, $232 \mathrm{p}$.

3. Drogues, santé et société, 2010, 7-223.

4. Office des Nations Unies Contre la Drogue et le Crime, Vienne, Méthodes recommandées pour l'identification et I'analyse du cannabis et des produits du cannabis, manuel destiné aux laboratoires nationaux d'analyse des drogues, New York, 2010.

5. El-Hilaly J, Hmammouchi M, Lyoussi B, Ethnobotanical studies and economic evaluation of medicinal plants in Taounate province (Northern Morocco), J Ethnopharm, 86, 2003, 149-158.

6. Habib A, Shujaul MK, Sajidul G, et al, Ethnobotanical Study of Upper Siran, Journal of Herbs. Spices Med Plants, 15, 2009, 86-97.

7. Suman K, Ethnobotanical study and socio-economic survey of Cannabis sativa. Indian Journal of Plant Sciences, 1, 2012, $114-119$.

8. Khan SM, Ud Din N, Ilyas M, et al, Ethnobotanical Study of Some Medicinal Plants of Tehsil Kabal, District Swat, KP, Pakistan, Med Aromat Plants, 4, 2015, 189.

9. Mohanraj $R$, Partha $M$, Sándor $B$, et al, Cannabidiol attenuates high glucose-induced endothelial cell inflammatory response and barrier disruption, American Journal of Physiology - Heart and Circulatory Physiology, 293, 2007, H610-H619.

10. Donald P Tashkin, Bertrand J Shapiro, Ira M Frank, Acute Pulmonary Physiologic Effects of Smoked Marijuana and Oral $\Delta 9$-Tetrahydrocannabinol in Healthy Young Men, N Engl J Med 289, 1973, 336-341.

11. Holdcroft A, Maze M, Doré C, et al, A Multicenter Doseescalation Study of the Analgesic and Adverse Effects of an Oral Cannabis Extract (Cannador) for Postoperative Pain Management, Anesthesiology, 104, 2006, 1040-6.

12. Myrtha N, Michele C, Steen Petersen-Felix, et al The analgesic effect of oral delta-9-tetrahydrocannabinol (THC), morphine, and a THC-morphine combination in healthy subjects under experimental pain conditions, Pain, 105, 2003, 79-88.

13. Schier AR, Ribeiro NP, Silva AC, et al, Cannabidiol, a Cannabis sativa constituent, as an anxiolytic drug, Revista Bras Psiquiatria, 34, 2012, S104-S117.

14. Gerald T DeLong, Carl E Wolf, Alphonse $\mathrm{P}$, et al, Pharmacological evaluation of the natural constituent of Cannabis sativa, cannabichromene and its modulation by $\Delta 9$-tetrahydrocannabinol. Drug and Alcohol Dependence, 112, 2010, 126-133.

15. Abir T El-Alfy, Kelly I, Keisha R, et al, Antidepressant-like effect of $\Delta 9$-tetrahydrocannabinol and other cannabinoids isolated from Cannabis sativa L. Pharmacology, Biochem Behavior, 95, 2010, 434-442.

16. Verhoeckx KC, Korthout HA, van Meeteren-Kreikamp AP, et al, Unheated Cannabis sativa extracts and its major compound THC-acid have potential immuno-modulating 
properties not mediated by CB1 and CB2 receptor coupled pathways, Inter Immunopharm, 6, 2006, 656-665.

17. Barbara R, Francesca $B$, Ester $P$, et al, Inhibition of colon carcinogenesis by a standardized Cannabis sativa extract with high content of cannabidiol, Phytomed, 21, 2014, 631639.

18. Nadine F, Robert R, Burkhard $H$, Antitumorigenic effects of cannabinoids Beyond apoptosis, Institute of Toxicology and Pharmacology, University of Rostock, Schillingallee 70, D18057 Rostock, Germany, 2009.

19. Lorenzo N, Alessandro Z, llaria S, et al, Characterization and antimicrobial activity of essential oils of industrial hemp varieties (Cannabis sativa L.), Fitoterapia, 81, 2010, 413-419.

20. Ibrahim AK, Radwan MM, Ahmed SA, et al, Microbial metabolism of cannflavin $A$ and $B$ isolated from Cannabis sativa, Phytochem, 71, 2010, 1014-1019.

21. Carrier EJ, Patel S, Hillard CJ, Endocannabinoids in neuroimmunology and stress, Curr Drug Targets CNS NeurolDisord, 4, 2005, 657e65.

22. Rajavashisth TB, Shaheen M, Norris KC, et al, Decreased prevalence of diabetes in marijuana users: cross-sectional data from the National Health and Nutrition Examination Survey (NHANES) III, BMJ, 2, 2012, e000494.

23. Wallace MS, Marcotte TD, Umlauf A, et al, Efficacy of Inhaled Cannabis on Painful Diabetic Neuropathy, J Pain, 16(7), 2015, 616-627.
24. Cousens K, DiMascio A, (-) Delta 9 THC as an hypnotic, An experimental study of three dose levels, Psychopharmacologia, 33(4), 1973, 355-64.

25. Feinberg I, Jones R, Walker JM, et al, Effects of high dosage delta-9 tetrahydrocannabinol on sleep patterns in man, Clin Pharmacol Ther, 17(4), 1975, 458-66.

26. Barratt ES, Beaver W, White $R$, The effects of marijuana on human sleep patterns, Biol Psychiatry, 8(1), 1974, 47-54.

27. Freemon FR, The effect of chronically administered delta-9tetrahydrocannabinol upon the polygraphically monitored sleep of normal volunteers, Drug Alcohol Depend, 10(4), 1982, 345-53.

28. Pranikoff $\mathrm{K}$, Karacan I, Larson EA, et al, Effects of marijuana smoking on the sleep EEG, Preliminary studies JFMA, 60(3), 1973, 28-31.

29. Callaway J, Hempseed as a nutritional resource: An overview, Euphytica, 140, 2004, 65-72.

30. Gakhar N, Goldberg E, Jing M, et al, Effect of feeding hemp seed and hemp seed oil on laying hen performance and egg yolk fatty acid content: Evidence of their safety and efficacy for laying hen diets, Poultry Science, 91, 2012, 701-711.

31. Neijat M, Gakhar N, Neufeld J, et al, Performance, egg quality, and blood plasma chemistry of laying hens fed hempseed and hempseed oil, Poultry Science, 2014, 93, 2827-2840.

Source of Support: None declared.

Conflict of Interest: None declared.

For any question relates to this article, please reach us at: editor@globalresearchonline.net New manuscripts for publication can be submitted at: submit@globalresearchonline.net and submit_ijpsrr@rediffmail.com 